\title{
INDUSTRIAL WASTEWATER AS AN ENABLER OF GREEN AMMONIA TO POWER VIA GAS TURBINE TECHNOLOGY
}

\author{
S. G. Hewlett*, D. G. Pugh, A. Valera-Medina, A. Giles, J. Runyon, \\ B. Goktepe, P.J. Bowen. \\ Cardiff University School of Engineering, \\ Cardiff, Wales, UK, CF24 3AA. \\ Email: hewlettsg4@cardiff.ac.uk, valeramedinaa1@cardiff.ac.uk
}

\section{ABSTRACT}

This experimental study follows on from detailed ChemkinPro numerical analyses assessing the viability of by-product ammonia $\left(\mathrm{NH}_{3}\right)$ utilization for power generation in gas turbines (GTS). This study looks specifically at $\mathrm{NH}_{3}$ in the industrial wastewaters of steelworks, resulting from the cleansing of coke oven gas (COG). The by-product $\mathrm{NH}_{3}$ is present in an aqueous blend of 60-70\% vol water and is normally destroyed.

An experimental campaign was conducted using a premixed swirl burner in a model GT combustor, previously employed in the successful combustion of $\mathrm{NH}_{3} /$ hydrogen blends, with favorable $N O_{x}$ and unburned fuel emissions. This study experimentally investigates the combustion performance of combining anhydrous and aqueous by-product $\mathrm{NH}_{3}$ in an approximate 50:50\% vol blend, comparing the performance with that of each ammonia source unblended. Green anhydrous $\mathrm{NH}_{3}$, a rapidly growing research topic, is a carbon-free energy vector for renewable hydrogen. Some potential benefits of combining the two sources are suggested.

Ammonia combustion presents two major challenges, poor reactivity and a potential for excessive $N O_{x}$ emissions. Prior numerical analyses predicted that $15 \%$ vol addition of steelworks $C O G$, at an inlet temperature of $550 \mathrm{~K}$, may provide sufficient support for raising the reactivity of the $\mathrm{NH}_{3}$-based fuels, whilst limiting undesirable emissions. Therefore, addition of 10, 15 and $20 \%$ vol COG to each $\mathrm{NH}_{3}$-based fuel was investigated experimentally at $25 \mathrm{~kW}$ power with inlet temperatures $>500 \mathrm{~K}$, at atmospheric pressure.

As nitric oxide (NO) emissions decrease significantly with increasing fuel-to-air ratio, experiments were conducted at equivalence ratios $(\Phi)$ between 1.0 and 1.3, the precise range of $\Phi$ for each blend being optimized according to the modeling predictions for emissions. Leading blends, anhydrous $\mathrm{NH}_{3}$ with $15 \%{ }_{\text {vol }}$ COG and the $50: 50 \%$ vol blend with $15 \%$ vol $C O G$, achieved $<100$ ppm and $<200$ ppm NO respectively.

Modest-sized steel plants produce $\sim 10$ metric tons of byproduct $\mathrm{NH}_{3} /$ day. Aspen Plus was used to model a BraytonRankine cycle with integrated recuperation. Adopting typical losses (48\% cycle efficiency) and $\sim 1.2 \mathrm{MPa}$ combustor inlet pressure, the net electrical power generation of $15 \%$ vol COG blended with 10 tonnes/day of aqueous industrial $\mathrm{NH}_{3}$ and 25 tonnes/day of anhydrous $\mathrm{NH}_{3}$ (i.e. achieving a 50:50\% vol blend) was $\sim 4.7 \mathrm{MW}, \sim 47 \%$ more power than for the same amount of anhydrous $\mathrm{NH}_{3}$ with $15 \%$ vol $\mathrm{COG}$. This significant increase, indicates how industrial $\mathrm{NH}_{3}$ could enable green $\mathrm{NH}_{3}$ to power.

Keywords: Ammonia, Gas Turbine, Industrial Wastewater, Swirl Flame, NO Emissions

\section{NOMENCLATURE}

$\begin{array}{ll}\text { AA } & \text { Anhydrous Ammonia } \\ \text { AFT } & \text { Adiabatic Flame Temperature } \\ \text { AqAV } & \text { Aqueous Ammonia Vapor } \\ \text { COG } & \text { Coke Oven Gas } \\ \text { GT } & \text { Gas Turbine } \\ \text { HRSG } & \text { Heat Recovery Steam Generator } \\ \text { LHV } & \text { Lower Heating Value } \\ \text { MFC } & \text { Mass Flow Controller } \\ \Phi & \text { Equivalence Ratio } \\ \text { S }_{L} & \text { Laminar Flame speed }\end{array}$




\section{INTRODUCTION}

This study investigates the potential for combining green ammonia, a carbon-free, renewably-produced hydrogen energy vector, with waste-stream ammonia found in industrial wastewaters, for power generation via gas turbines (GT).

\subsection{Green ammonia}

Hydrogen produced via the electrolysis of water using renewable electricity is termed green hydrogen. Pure, anhydrous ammonia (AA) manufactured using a green hydrogen feed and nitrogen from air, is termed green ammonia. When green ammonia is used to generate power, the cycle from power-togas-to-power is completed. In this manner, green ammonia is considered a potential enabler for the deployment of renewable hydrogen [1-3].

The conversion of hydrogen to ammonia is energy intensive, requiring 7.8 MWh of energy per metric ton (tonne) under best practice, using natural gas [4]. Despite the energy intensity of production, the conversion is favored due to the modest conditions required for ammonia's storage and transport. Anhydrous ammonia can be stored as a liquid at a modest

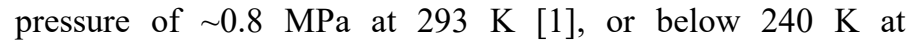
atmospheric pressure. By contrast, liquefying hydrogen requires a temperature of $20 \mathrm{~K}$ at atmospheric pressure $[5,6]$, yet the hydrogen density of liquid hydrogen is still considerably lower than that of liquid ammonia, as shown in Fig.1.

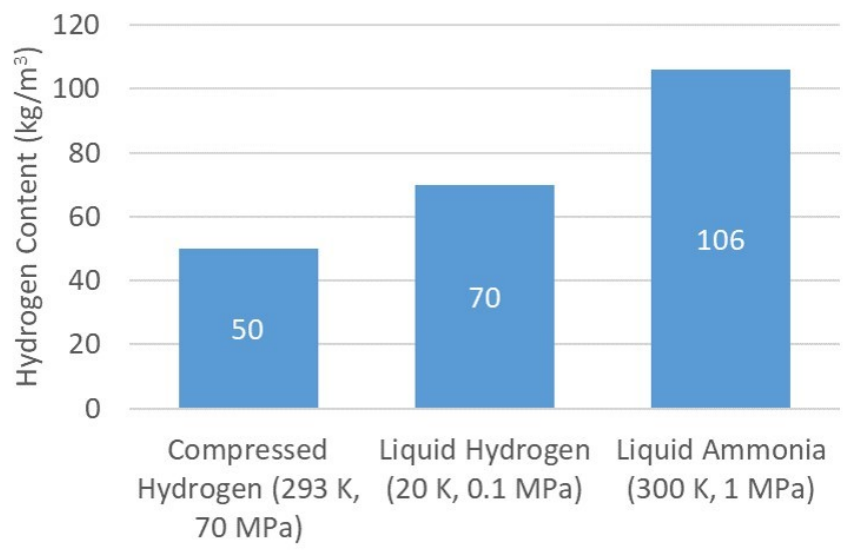

FIGURE 1. HYDROGEN DENSITIES OF AMMONIA AND HYDROGEN UNDER VARYING CONDITIONS [5, 6].

With a global trade in 2018 of approximately $140 \mathrm{Mt}$ (nitrogen equivalent) [7], ammonia has large scale, established transport and handling networks, unlike hydrogen. When comparing with other liquid fuels, AA has a lower heating value (LHV) of $18.6 \mathrm{MJ} / \mathrm{kg}$, similar to methanol and half that of diesel.

\subsection{By-product ammonia}

In contrast to the energy intensive production of ammonia, many industrial waste streams contain significant amounts of unwanted and readily available by-product ammonia. These industrial wastewaters could be used to augment the ammonia available from renewable sources, thus encouraging earlier and larger scale development of the infrastructure required to generate power from ammonia-based fuels.

Many industries handling material of organic origin have ammonia and hydrogen sulfide $\left(\mathrm{H}_{2} \mathrm{~S}\right)$ in their material flows. Obvious examples include agriculture, sewage treatment and biomass gasification. Fossil fuels are also of organic origin, so coal carbonization and oil refining have significant aqueous waste streams, termed sour waters, containing these two impurities.

This paper focuses on ammonia waste streams in the steel industry for two main reasons. First, coke is a reductant and fuel source in the blast furnace and the carbonization of coal to coke produces a particularly concentrated ammonia waste stream of $\sim 3 \mathrm{~kg}$ per tonne of coke [8]. The ammonia is captured during the cleansing of coke oven gas (COG), the volatile component of coal [9]. Secondly, crude steel manufacture using a blast furnace produces pig iron. After the blast furnace, the basic oxygen furnace decarbonizes pig iron with oxygen, during its conversion to steel. This oxygen is sourced via air separation, resulting in a nitrogen by-product, locally available for green or other ammonia manufacture. Although this study considers green ammonia as a source of AA, ammonia can also be produced with hydrogen obtained from COG [9]. This could be of particular interest in China, where $49 \%$ of global crude steel is produced, $91 \%$ via blast furnaces [10] and where, in 2013 , only $20 \%$ of COG was reported as being utilized as fuel [11].

COG is composed predominantly of hydrogen $(\sim 60 \%$ vol $)$, methane $\left(\sim 24 \%_{\mathrm{vol}}\right)$ and carbon monoxide $\left(\sim 7 \%_{\mathrm{vol}}\right)[8,12]$. In volumetric terms, COG has a higher heating value of 17-18 $\mathrm{MJ} / \mathrm{Nm}^{3}[8,12,13]$, around half that of methane. Raw COG is laden with impurities, including $\mathrm{NH}_{3}$ and $\mathrm{H}_{2} \mathrm{~S}$ in similar concentrations [8]. Under typical coke oven processing conditions (i.e. $\geq 1200 \mathrm{~K}$ ), ammonia in COG constitutes around $10-15 \%$ of all the nitrogen originally present in the coal [9].

Ammonia presents a serious threat to human health and the environment when poorly managed. Ammonia is a toxic and corrosive substance and is especially dangerous to aquatic environments. Therefore, it is necessary to remove ammonia and other contaminants from COG before utilization as a fuel.

$\mathrm{NH}_{3}$ and $\mathrm{H}_{2} \mathrm{~S}$ dissolve readily in water. Therefore, COG cleansing processes conventionally use water to strip the $\mathrm{NH}_{3}$ and $\mathrm{H}_{2} \mathrm{~S}$ from COG. The processing produces an ammonia-rich waste stream which undergoes a final stage of recovery or destruction. This stream is maintained as a vapor at $\sim 360 \mathrm{~K}$ and has a typical composition as shown in Fig. $2[13,14]$. The ammonia-rich stream in Fig. 2 has a LHV of $6.8 \mathrm{MJ} / \mathrm{kg}$ and will henceforth be referred to as aqueous ammonia vapor (AqAV), to concisely differentiate it from AA.

Approximately 450 to $480 \mathrm{~kg}$ of coke is consumed for every tonne of steel produced, generating $\sim 1.5 \mathrm{~kg}$ of ammonia, [15, 16]. Therefore, a modest sized integrated steelworks (e.g. $2.7 \mathrm{Mt}$ steel per annum) will produce in excess of 3,500 tonnes of ammonia from its coke ovens each year, equivalent to approximately 10 tonnes per day. Consequently, the steel industry has a long history of managing by-product ammonia. 


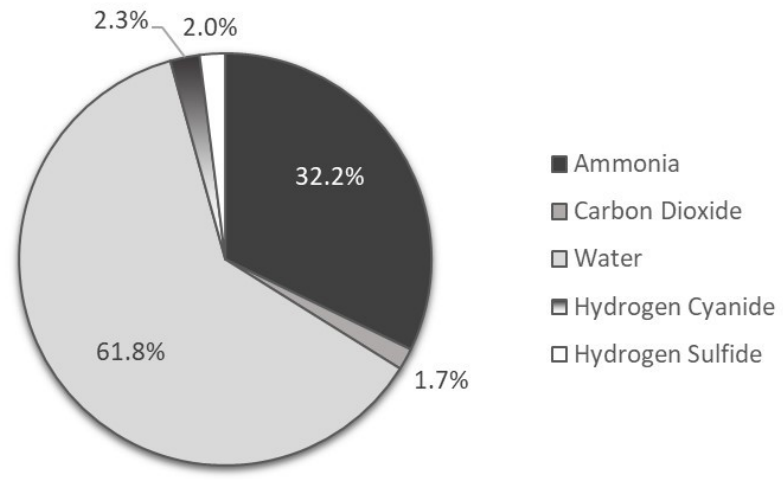

FIGURE 2. TYPICAL COMPOSITION (\%VL) OF STEELWORKS AQUEOUS AMMONIA VAPOR (AqAV) $[13,14]$

Several methods can be used to recover, rather than destroy the ammonia. These include reacting with sulfuric acid to produce ammonium sulfate fertilizer and the PHOSAM process for the recovery of $>99 \%$ purity AA $[9,14]$. Currently $\sim 72 \%$ of global ammonia is produced via the Haber-Bosch process, utilizing hydrogen from natural gas [4]. In comparison to this large-scale process, ammonia recovery from industrial wastewater is uneconomical, resulting in moves to destroy rather than recover the ammonia, either through its catalytic destruction or incineration. These market conditions could of course change if $\mathrm{CO}_{2}$ emissions, from the use of natural gas $(\sim 1.6$ tonnes per tonne of AA [4]), were costed to significantly impair the economics of producing synthetic ammonia.

Energy recovery from the destruction of industrial byproduct ammonia is not a legal requirement in the European Union [8]. While heat recovery from the destruction of industrial AqAV is often practiced [13, 14, 17], no evidence has been found of direct combustion of AqAV in GT, or any other type of power generation technology. GT combustion of AA on the other hand, was first investigated in the 1960s [18] and with recent interest in power-to-gas-to-power via green ammonia, research in this field has undergone a recent surge in activity [19-26].

\subsection{Ammonia combustion}

Two major challenges encountered when utilizing ammonia as a fuel are its comparatively low reactivity [18] and the potential for very high exhaust $\mathrm{NO}_{\mathrm{x}}$ concentrations [27]. Characteristics of low reactivity include low laminar burning velocity $\left(\mathrm{S}_{\mathrm{L}}\right)$, high minimum ignition energy and narrow flammability range. These poor combustion characteristics are especially problematic when using existing GT technology designed for use with conventional fuels. The reactivity of AqAV is naturally considerably poorer than for AA, given the substantial water component $(\sim 60 \%$ vol $)$.

One method used to address the issue of low reactivity is to use more reactive support fuels in conjunction with ammoniabased fuels. In 1967, Verkamp et al. [18] found that with $28 \%_{\mathrm{vol}}$ hydrogen addition to $\mathrm{AA}$, to simulate pre-combustion thermolysis of the ammonia, AA adopted many of the combustion characteristics of conventional fuels. Hydrogen addition increases the $S_{L}$ of ammonia [1].

A number of related studies have taken place at Cardiff University's Gas Turbine Research Centre investigating hydrogen and methane as potential support fuels for ammonia combustion [20-24]. With the use of these support fuels, premixed swirling flames were established across a narrow range of operable equivalence ratios $(\Phi)$. The same premixed, model GT combustor was employed for this experimental campaign.

As with hydrogen addition, fuel/air preheating also increases reactivity and consequently the $\mathrm{S}_{\mathrm{L}}$ of ammonia blends. Preheating has been shown to improve efficiencies by decreasing unburned fuel concentrations [25]. However, excessive preheating increases thermal $\mathrm{NO}_{\mathrm{x}}$ production.

This work follows on from a detailed numerical study (see [28]) utilizing Chemkin-Pro, which used the ammonia/methane compatible mechanisms of Tian et al. [29] and Okafor et al. [26] for 1-D $S_{L}$ simulations and for predicting emissions in a 1-D reactor network model. The reactor network comprised a cluster of three perfectly-stirred reactors representing ignition, central recirculation and flame zones, followed by a plug flow reactor for modeling the post flame zone. For atmospheric pressure, an inlet temperature of $550 \mathrm{~K}$ was predicted as sufficient for aiding reactivity whilst minimizing thermal $\mathrm{NO}_{\mathrm{x}}$ formation, which would result from higher inlet temperatures.

With an inlet of $550 \mathrm{~K}$, the addition of approximately $15 \%$ vol COG was numerically found to optimally balance improvements in performance against the production of nitric oxide (NO), carbon monoxide (CO) and ammonia $\left(\mathrm{NH}_{3}\right)$ in both the aqueous and AA fuels [28]. As COG is often produced in amounts exceeding its utilization and subsequently flared [11, 30], it is ideal for blending to enhance $\mathrm{NH}_{3}$ combustion.

$\mathrm{NO}_{\mathrm{x}}$ formation in nitrogen-rich fuels can reach levels far greater than equilibrium, as formation is more closely related to kinetics (fuel $\mathrm{NO}_{\mathrm{x}}$ ) than peak temperatures (thermal $\mathrm{NO}_{\mathrm{x}}$ ) [27], in contrast to conventional natural gas. Fuel-rich combustion is an effective method for limiting $\mathrm{NO}_{\mathrm{x}}$ formation, thus staged combustion has been shown to have the potential to lower overall $\mathrm{NO}_{\mathrm{x}}$ emissions [13, 27, 31, 32]. In staged combustion, a fuelrich stage, consuming the majority of the fuel, is followed by a secondary fuel-lean stage, completing the combustion process, consuming primarily unreacted $\mathrm{H}_{2}$. High levels of unburned $\mathrm{NH}_{3}$ entering the lean stage greatly increases overall $\mathrm{NO}$ for the system [19, 32].

Experiments by Pugh et al. [22], utilizing the same model GT combustor as used in this study, showed that steam addition has the potential to lower $\mathrm{NO}_{\mathrm{x}}$ emissions concentrations in premixed $\mathrm{NH}_{3} / \mathrm{H}_{2}$ swirling combustion. Thus, the water component, in an $\mathrm{AA} / \mathrm{AqAV}$ blend, could potentially lower the $\mathrm{NO}_{\mathrm{x}}$ emissions concentrations when compared with AA alone.

\section{EXPERIMENTAL INVESTIGATION}

As in the simulations, the target experimental inlet temperature and operating pressure for the premixed fuel and air 
were $550 \mathrm{~K}$ and $0.1 \mathrm{MPa}$ respectively. Fuel flow rates equivalent to $25 \mathrm{~kW}$ power (LHV) were used for all mixtures.

As previously shown in Fig. 2, AqAV contains trace $\mathrm{H}_{2} \mathrm{~S}$, $\mathrm{HCN}$ and $\mathrm{CO}_{2}$. These components were discounted and a surrogate AqAV was formulated composed of $38.35 \% \mathrm{vol}_{\mathrm{vol}} \mathrm{NH}_{3}$ and $61.65 \%$ vol water vapor. This formulation increased the amount of $\mathrm{NH}_{3}$ to compensate for the loss of heating value resulting from the absence of $\mathrm{H}_{2} \mathrm{~S}$ and $\mathrm{HCN}$, and increased the water component to replicate the specific heat capacity of the missing inert $\mathrm{CO}_{2}$. The delivery of the surrogate AqAV was achieved by combining a preheated air/steam line with anhydrous ammonia (and $\mathrm{COG}$ ) in the mixing plenum, upstream of the burner.

To reduce costs, the COG composition used for the experimental work was slightly different to the representative $\mathrm{COG}$, as derived from literature and used in the numerical modeling. Table 1 shows the relative compositions, with the experimental blend lacking only the combined $2.2 \%$ vol of ethene $\left(\mathrm{C}_{2} \mathrm{H}_{4}\right)$ and ethane $\left(\mathrm{C}_{2} \mathrm{H}_{6}\right)$.

On a mass basis, experimental COG and that derived from the literature had LHVs of 39.9 and $40.6 \mathrm{MJ} / \mathrm{kg}$ respectively.

TABLE 1. COMPARISON OF THE COG COMPOSITION USED EXPERIMENTALLY WITH THAT DERIVED FROM THE LITERATURE

\begin{tabular}{|l|ccccccc|}
\hline \multirow{2}{*}{ COG } & \multicolumn{7}{|c|}{ Mole Fractions of Component Gases } \\
Composition & $\mathrm{H}_{2}$ & $\mathrm{CH}_{4}$ & $\mathrm{CO}$ & $\mathrm{N}_{2}$ & $\mathrm{CO}_{2}$ & $\mathrm{C}_{2} \mathrm{H}_{4}$ & $\mathrm{C}_{2} \mathrm{H}_{6}$ \\
\hline Literature & 0.608 & 0.242 & 0.07 & 0.039 & 0.019 & 0.017 & 0.005 \\
Experimental & 0.61 & 0.26 & 0.07 & 0.04 & 0.02 & 0 & 0 \\
\hline
\end{tabular}

\subsection{Rationale for 50:50\%vol AA/AqAV blend}

Figure 3 shows numerical simulation results for $S_{L}$ of AA with $15 \%$ vol $\mathrm{COG}$, at a proposed optimal range of $\Phi$ and an inlet temperature of $550 \mathrm{~K}$, using the Okafor et al. mechanism [26]. This optimal range (shaded points) reflects a narrow range of $\Phi$ where reactor network modeling shows both $\mathrm{NO}$ and $\mathrm{NH}_{3}$ emissions can be simultaneously minimized in the primary stage of staged combustion.

Within the optimal range, the $\mathrm{S}_{\mathrm{L}}$ of AA with $15 \%$ COG was found to be close to that of very lean methane combustion, using the GRI-Mech 3.0 mechanism [33]. This suggests an AA with $15 \%$ COG blend may be capable of stable flames in existing natural gas combustors. However, the AqAV with $15 \%$ COG blend failed to reach similar simulated $\mathrm{S}_{\mathrm{L}}$, suggesting that stabilizing the flame could be particularly challenging for this mix.

Combining AA with AqAV, mimicking an effective reduction of water in $\mathrm{AqAV}$, is therefore suggested to increase $\mathrm{S}_{\mathrm{L}}$ and further help to stabilize the flame. Figure 3 shows the improvement in simulated $\mathrm{S}_{\mathrm{L}}$ for a $50 \%_{\mathrm{vol}} \mathrm{AA}$ to $50 \%_{\mathrm{vol}} \mathrm{AqAV}$ i.e. 50:50 blend, over that of AqAV under the same inlet conditions and COG percentage. Shaded points on this line represent an anticipated optimal operating range of $\Phi$ given those predicted for the uncombined ammonia-based fuels.

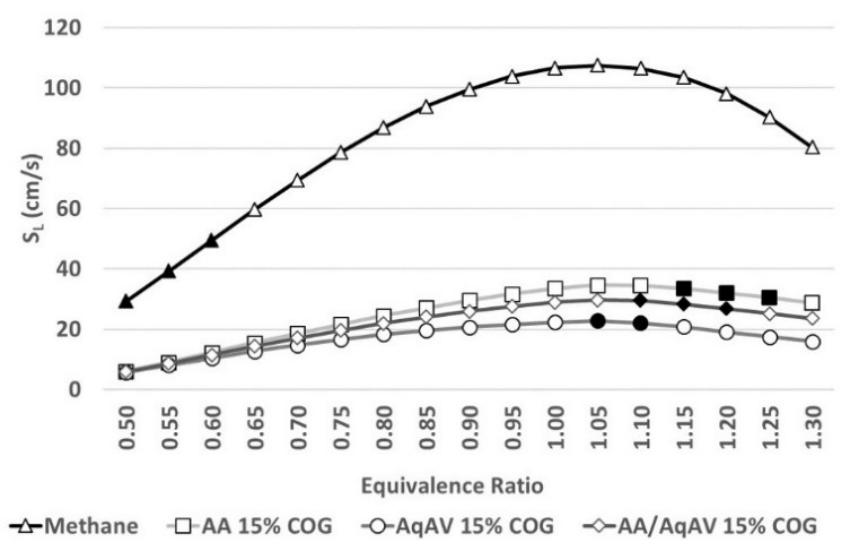

FIGURE 3. $S_{L}$ AS A FUNCTION OF $\Phi$ FOR AA, AqAV AND 50:50\% AA/AqAV WITH 15\% $\%_{\text {vol }}$ COG AND PURE METHANE (550 K, $\left.0.1 \mathrm{MPa}\right)$

Other potential benefits result from combining the two ammonia sources, not all related to combustion performance. For example, when using the 50:50 AA/AqAV blend:

- The water in the AqAV fraction increases the mass flow compared with using AA alone, increasing the power generation potential.

- By taking advantage of the move to green ammonia power generation, the opportunity exists to recover the energy potential of ammonia and hydrogen cyanide in industrial waste streams. This is often lost through destruction without energy recovery.

- The same industries that produce by-product ammonia also produce potential hydrogen and/or methane containing support fuels such as COG, biogas and syngas. This gives these industries the potential to act as ammonia power generation 'hubs' to which green AA could be transported.

- Combining AA and AqAV delivers an increase in the potential scale of operation over that of green ammonia alone. Increased scale can lead to efficiency and emissions improvements (e.g. the justification of 'bottoming' cycles and investment in $\mathrm{NO}_{\mathrm{x}}$ abatement technologies).

Thus, this study aims to select combined (AA with AqAV) and uncombined (AA or AqAV) blends which optimize the primary fuel-rich stage by simultaneously minimizing $\mathrm{NO}$ and $\mathrm{NH}_{3}$ emissions, under the conditions modeled. These blends must also be found capable of stable combustion. A further aim is to compare cycle efficiencies and net power generated by the selected blends in an Aspen Plus simulated cycle, investigating possible scenarios for ammonia-based fuels utilization.

To represent a 50:50 blend of $\mathrm{AA}$ with $\mathrm{AqAV}$, the water component was approximately halved, giving a $70 \% \mathrm{vol}_{\mathrm{NH}} \mathrm{NH}_{3}$ to $30 \%{ }_{\text {vol }} \mathrm{H}_{2} \mathrm{O}$ mix.

Target $\Phi$ values studied were \pm 0.05 either side of the optimal ranges for each blend (at 0.05 intervals). This gave an experimental $\Phi$ range of 1.0 to 1.15 for AqAV/COG and 1.05 to 1.3 for AA/COG. For the 50:50 AA/AqAV blend with COG, $\Phi$ values between 1.0 and 1.2 were studied. 
As previously stated, numerical modeling suggested $15 \%$ COG addition is optimal for both AA and AqAV. To verify this, 10,15 and $20 \%$ vol COG addition was investigated for each of the three ammonia-based fuels, giving 9 potential fuel blends in total. All blends are described on a volumetric (molar) basis.

\subsection{Experimental setup}

As in previous studies, a premixed generic swirl burner with a geometric swirl number of 0.8 was employed [22-24]. The burner assembly, shown in Fig. 4, is representative of a typical industrial gas turbine. The $18 \mathrm{~mm}$ OD instrumentation lance (Fig. 4a) provides a bluff body stabilization location and temperature measurement within the swirl burner exit nozzle (Fig. 4d). The premixed, preheated air and fuel enter the inlet plenum (Fig. 4b) and proceed to the mixing plenum (Fig. 4c) immediately upstream of the swirl burner. The burner exit is contained within an open-ended cylindrical quartz tube confinement (Fig. 4e), $100 \mathrm{~mm}$ in diameter and $385 \mathrm{~mm}$ in length, housed inside a pressure casing (Fig. 4f). The expansion ratio of the confinement's internal diameter to the internal diameter of the burner exit nozzle is 2.5. The pressure casing is fitted with quartz windows (Fig. 4g) for non-intrusive, optical observations of the flame structure in the axial plane. The use of this pressure vessel eliminates any atmospheric dilution of the exhaust emissions and will be used for the pressurized combustion experiments in the future.

Steam delivery was achieved by siphoning pressurized water from a Millipore $20 \mathrm{~L}$ pressure vessel, into a $24 \mathrm{~kW}$ electric heat exchanger in a 'double pass' arrangement. The water flow was regulated using a coriolis mass flow controller (MFC). An electric heat trace was used to maintain heat gains between passes and between the outlet from the heat exchanger to the insulated, preheated air line where the water was injected as steam at atmospheric pressure.

The plenum and burner inlet were preheated to the specified temperature between 502 and $533 \mathrm{~K}$ using inline air heaters, which also preheated the fuel. This was used to simulate heat exchange from the exhaust to the fuel/air premix using a recuperator.

As with the water, flow rates for ammonia vapor and COG were also remotely controlled via coriolis MFCs. Air flow was controlled using proportional valves and measured with a coriolis meter.

\subsection{Gas analysis method}

Approximately $200 \mathrm{~mm}$ downstream of the quartz tube exit, a nine-hole equal-area gas analysis probe is situated centrally within the flow of the combustion products. Sampled gases are water-cooled to $433 \mathrm{~K}$ in the probe, in accordance with ISO 11042 [34]. The sampled gases are filtered, electrically heated to maintain $433 \mathrm{~K}$ as the sample is delivered to the gas analyzers, preventing any components cooling below their respective dew points.

Due to the fuel-rich combustion conditions and the presence of carbon in the COG feed, $\mathrm{CO}$ concentrations were especially high and hence, the readings were out of range. To overcome this issue, dry dilution air was added to the sampled product gases, lowering the concentrations to within the measurement range. The fuel-rich combustion and continuous presence of $\mathrm{CO}$ in the products allowed for the assumption that all oxygen present in the diluted sample was contributed by the dilution air and not by reactants. The percentage oxygen present in the products was continuously logged. This logged data, when compared to the pre-test ambient average oxygen concentration, was used to calculate dilution values for each experimental condition.

$\mathrm{CO}_{2}, \mathrm{CO}$ and $\mathrm{O}_{2}$ were passed through a chiller and analyzed dry in a Signal $9000 \mathrm{MGA}$ multi gas analyzer. $\mathrm{CO}_{2}$ and $\mathrm{CO}$ were measured using a non-dispersive, infrared analyzer, while $\mathrm{O}_{2}$ was measured using a paramagnetic sensor.

NO was analyzed hot and wet in a Signal 4000VM heated vacuum chemiluminescence analyzer, so the readings required normalization to dry equivalent conditions. The product water fraction was taken from equilibrium modeling for each case. The $\mathrm{NO}_{\mathrm{x}}$ analyzer has an accuracy of $> \pm 1 \%$ of range.

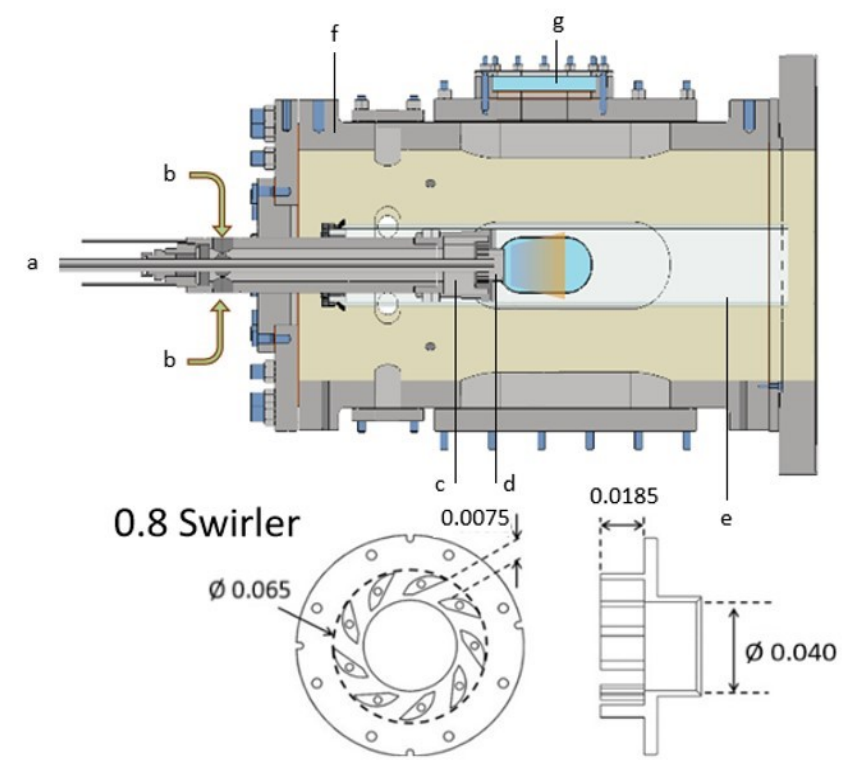

FIGURE 4. CROSS-SECTION OF GENERIC SWIRL BURNER ASSEMBLY AND GEOMETRY OF THE SWIRL BURNER (DIMENSIONS IN METERS)

Ammonia was reacted with $\mathrm{O}_{2}$ at $1023 \mathrm{~K}$, over a platinum on alumina catalyst, in a Signal 410 ammonia converter. The NO (and water vapor) product was sent to the NO analyzer and was analyzed wet in the same manner as the NO previously mentioned. The system allowed samples to be exchanged between the direct feed from the gas probe and the outlet of the ammonia converter. Readings for $\mathrm{NO}$ and $\mathrm{NH}_{3}$ were therefore taken alternately for each experimental condition, the direct $\mathrm{NO}$ readings being subtracted from those including the converted ammonia, allowing for the conversion efficiency of $81 \%$ (as found during analyzer calibration). Fluctuations in air dilution were considered by recording oxygen concentrations for each of the NO and ammonia sampling periods separately within each 
condition. All figures show the precise experimental $\Phi$ as derived from the data.

After accounting for dilution, all emissions concentrations were calculated as dry, and referenced to $15 \%$ excess $\mathrm{O}_{2}$, as per the regulatory requirements for GT technology in the European Union [35]. $\mathrm{NO}_{2}$ is not included for simplicity, as it is considered consistently scaled to $\mathrm{NO}$ and a minor component of $\mathrm{NO}_{\mathrm{x}}$ in ammonia combustion.

\section{EXPERIMENTAL RESULTS AND DISCUSSION}

Due in part to the low air flows required for ammonia combustion, especially under fuel-rich conditions, the air preheat limited the operating temperatures to between 502 and $533 \mathrm{~K}$ with the lower inlet temperatures tending to occur at higher $\Phi$. Combustor inlet pressure was $0.109 \mathrm{MPa}$.

The AqAV/COG readings could only be taken for $20 \%$ COG addition. The AqAV with $15 \%$ and $10 \%$ COG were too unstable or incapable of sustaining a viable flame. This agrees with predictions based on the low $\mathrm{S}_{\mathrm{L}}$ for the AqAV blends under these conditions (see Fig. 3). For 20\% COG, at $\Phi=1.15$, the flame structure underwent frequent transition. Likewise, the flame for $\mathrm{AA} / \mathrm{AqAV}$ with $10 \% \mathrm{COG}$ at $\Phi=1.2$, was too unstable for safe operation, lifting off the burner. It is expected that an increased inlet temperature $(\sim 550 \mathrm{~K})$ would enable stable operation at this condition as suggested by the kinetic modeling.

\subsection{Carbon monoxide (CO) emissions}

As expected, $\mathrm{CO}$ emissions increased significantly with increasing $\Phi$. As Fig. 5 shows, CO emissions are marginally higher for the AA/AqAV blends than the AA blends. This increase in unburned fuel concentrations is due to the presence of water lowering the reactivity, e.g. the adiabatic flame temperature (AFT) and $\mathrm{S}_{\mathrm{L}}$, of the $\mathrm{AA} / \mathrm{AqAV}$ blends.

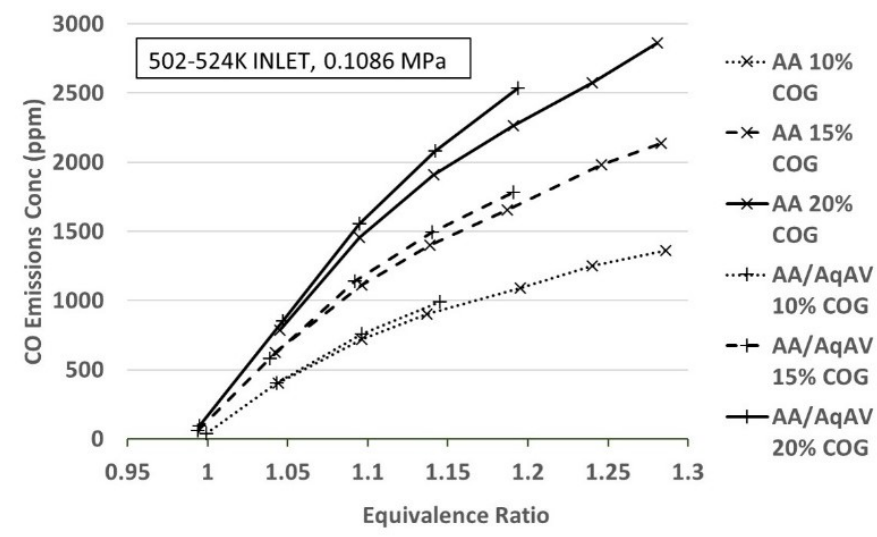

FIGURE 5. CO EMISSIONS BY EQUIVALENCE RATIO FOR AAAND AA/AqAV WITH 10, 15 AND 20\% $\%_{\text {vol }}$ COG (DRY, 15\% O ${ }_{2}$ )

The excessive $\mathrm{CO}$ concentrations highlight the need for a subsequent lean stage, to complete CO burnout. Naturally, CO emissions are higher for the mixes with higher percentages of $\mathrm{COG}$, due to the increased $\mathrm{CH}_{4}$ component.

\subsection{Nitric oxide (NO) and ammonia $\left(\mathrm{NH}_{3}\right)$ emissions}

In the flame zone, fuel bound nitrogen reacts rapidly with oxygen to produce NO. With less air at higher $\Phi$, concentrations of unburned fuel are higher and the reactivity of the fuel/air mix is lower. Unburned ammonia dissociates into amine radicals $\mathrm{NH}_{2}, \mathrm{NH}$ and $\mathrm{N}$ which react with $\mathrm{NO}$ to form water and $\mathrm{N}_{2}$. This is why $\mathrm{NO}$ concentrations decrease with increasing $\Phi$, as shown in Figs. 6, 7 and 8.

Similarly, less supporting fuel lowers mix reactivity. Thus, less COG results in more unburned ammonia to react with $\mathrm{NO}$, explaining why $\mathrm{NO}$ concentrations are lower and $\mathrm{NH}_{3}$ concentrations generally higher with less COG.

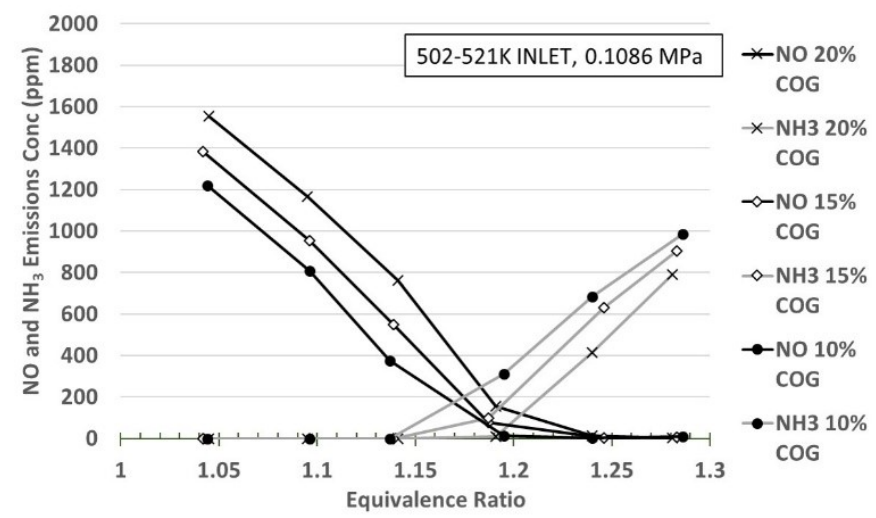

FIGURE 6. NO AND $\mathrm{NH}_{3}$ EMISSIONS BY EQUIVALENCE RATIO FOR AA WITH 10, 15 AND 20\% ${ }_{\text {vol }}$ COG (DRY, $15 \% \mathrm{O}_{2}$ )

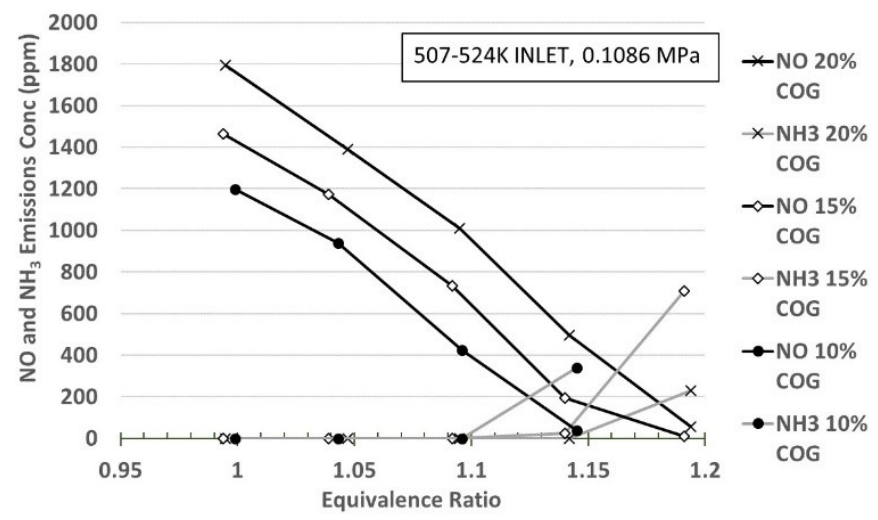

FIGURE 7. NO AND $\mathrm{NH}_{3}$ EMISSIONS BY EQUIVALENCE RATIO FOR 50:50\% $\%_{\text {vol }}$ AA/AqAV WITH 10, 15 AND 20\% $\%_{\text {vol }}$ COG (DRY, $15 \%$ $\mathrm{O}_{2}$ )

The AA blends (Fig. 6) have higher NO concentrations than the equivalent $\mathrm{AA} / \mathrm{AqAV}$ blends at the same $\Phi$. This is because the addition of water reduces the flame temperature and reactivity of the $\mathrm{AA} / \mathrm{AqAV}$ blends.

Without preheating, thermal NO has been found negligible compared to fuel NO in ammonia combustion [36]. However, increasing burner inlet temperature and supporting fuels percentage, enhances the role of thermal NO. Therefore, some of the reduction in $\mathrm{NO}$ with lower reactivity is due to lower AFT, reducing thermal $\mathrm{NO}_{\mathrm{x}}$ production. 


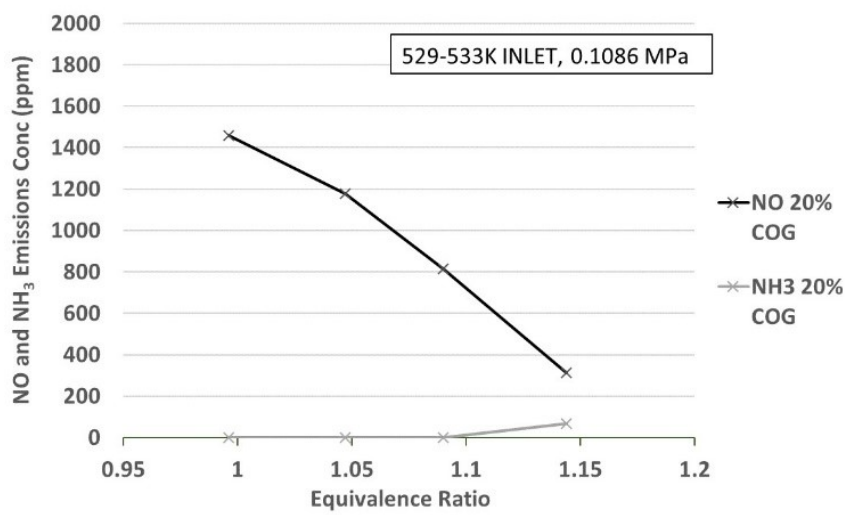

FIGURE 8. NO AND $\mathrm{NH}_{3}$ EMISSIONS BY EQUIVALENCE RATIO FOR AqAV WITH 20\% ${ }_{\text {vol }}$ COG (DRY, 15\% O $\mathrm{O}_{2}$ )

Thus, NO emissions decrease with increasing $\Phi$ and $\mathrm{NH}_{3}$ emissions increase substantially above a certain value of $\Phi$ for each fuel mixture (see Figs. 6 and 7). $\mathrm{NH}_{3}$ emissions must be minimized before the lean second stage to avoid high rates of NO production at $\Phi<1[19]$.

At $\Phi=1.187$, the AA with $15 \%$ COG blend had its lowest combined $\mathrm{NO}$ and $\mathrm{NH}_{3}$ readings of 174 ppm (76 and 98 respectively). The $20 \%$ COG blend was also capable of a similar lowest combined reading of $162 \mathrm{ppm}$ for $\mathrm{NO}$ and $\mathrm{NH}_{3}$ (155 and 7 respectively) at $\Phi=1.191$. The 15 and $20 \%$ COG blends exhibited improved combined emissions performance over the $10 \%$ COG blend. Given the similar values for lowest combined $\mathrm{NO} / \mathrm{NH}_{3}$ emissions in the 15 and $20 \%$ COG blends, the $15 \%$ COG blend was selected for the cycle analysis, due to the lower requirement for carbon-containing support fuel.

The lowest combined $\mathrm{NO} / \mathrm{NH}_{3}$ reading for the $\mathrm{AA} / \mathrm{AqAV}$ with $15 \%$ COG blend, was obtained at $\Phi=1.140$. This combined reading of $219 \mathrm{ppm}(196 \mathrm{ppm} \mathrm{NO}$ and $23 \mathrm{ppm} \mathrm{NH}$ ) was less than the lowest combined measure for the $\mathrm{AA} / \mathrm{AqAV}$ with $20 \%$ COG blend, which was 283 ppm (54 ppm NO and $229 \mathrm{ppm} \mathrm{NH}_{3}$ ) at $\Phi=1.194$. Once again, the more unstable nature of the $10 \%$ COG flame, favors the other two AA/AqAV blends. The lower requirement for carbon-containing support fuel, lower combined emissions and far lower unburned $\mathrm{NH}_{3}$ leaving the primary stage, makes the $\mathrm{AA} / \mathrm{AqAV}$ with $15 \% \mathrm{COG}$ the leading $\mathrm{AA} / \mathrm{AqAV}$ blend for cycle analysis.

Based on these measurements, the $\mathrm{AA} / \mathrm{AqAV}$ blends are less favorable than the equivalent AA blends due to their higher combined emissions, showing that despite lower NO at the same $\Phi$, water addition does not guarantee lower combined emissions overall.

Experimental results were used to improve heat losses, recirculation ratios and residence times for the reactor network model described in Section 1.3. Heat losses and residence times in perfectly-stirred reactors 1 to 3 were $0.1 \mathrm{~kW} / 0.001 \mathrm{~s}, 0.8$ $\mathrm{kW} / 0.005 \mathrm{~s}$ and $0.8 \mathrm{~kW} / 0.02 \mathrm{~s}$ respectively. Recirculation between reactors was modified to $30 \%$. Heat loss in the plug flow reactor was modeled for $0.3 \mathrm{~kW} / \mathrm{cm}$. The improved reactor network model was used to predict $\mathrm{H}_{2}$ concentrations as a fraction of all products leaving the primary combustor. For AA with $15 \% \operatorname{COG}(\Phi=1.2)$ and AA/AqAV with $15 \% \operatorname{COG}(\Phi=$ 1.15) predicted $\mathrm{H}_{2}$ concentrations were 5.1 and $3.7 \%_{\text {vol }}$ respectively.

\subsection{Optimizing $\Phi$ using laminar burning velocity}

The equivalence ratio was varied by 0.05 , which does not necessarily capture $\mathrm{NO} / \mathrm{NH}_{3}$ emissions at their absolute minimum. An optimal $\Phi$, or $\Phi_{\text {opt }}$, whereby both $\mathrm{NO}$ and $\mathrm{NH}_{3}$ can be simultaneously minimized for each blend, is reached when $\mathrm{NH}_{3}$ and $\mathrm{NO}$ concentrations are equal.

The values of $\Phi_{o p t}$ taken from Figs. 6 and 7 (to the nearest 0.005) are shown in Table 2. Also in Table 2, the $S_{L}$ for each blend at its $\Phi_{\text {opt }}$ has been simulated using the Okafor et al. mechanism [26] in Chemkin-Pro. Temperatures and pressures used in the simulations are those of the experimental condition nearest to each blends' $\Phi_{o p t}$.

The results in Fig. 9 use the values in Table 2 to show a strong positive linear correlation for $\Phi_{\text {opt }}$ against $\mathrm{S}_{\mathrm{L}}$ for the six $\mathrm{AA}$ and $\mathrm{AA} / \mathrm{AqAV}$ blends. A trend line passes through, or near, the six points and is then extrapolated (dotted trend line). This trend is useful for predicting which values of $\Phi_{\text {opt }}$ are likely for any similar blend by modeling its $\mathrm{S}_{\mathrm{L}}$. This trend was not identified when correlating $\Phi_{\text {opt }}$ with AFT.

TABLE 2. $\Phi_{\text {opt }}$ FOR BLENDS AND THEIR RESPECTIVE LAMINAR BURNING VELOCITIES

\begin{tabular}{|c|c|c|c|c|c|}
\hline \multicolumn{2}{|c|}{ Fuel } & \multirow{2}{*}{$\mathrm{P}(\mathrm{MPa})$} & \multirow{2}{*}{ Inlet $\mathrm{T}(\mathrm{K})$} & \multirow{2}{*}{$\Phi_{o p t}$} & \multirow{2}{*}{$\mathrm{S}_{\mathrm{L}}(\mathrm{cm} / \mathrm{s})$} \\
\hline COG \% & Ammonia & & & & \\
\hline $20 \%$ COG & AA & 0.1088 & 512.5 & 1.205 & 29.157 \\
\hline $15 \%$ COG & AA & 0.1088 & 506.3 & 1.185 & 26.461 \\
\hline $10 \%$ COG & $\mathrm{AA}$ & 0.1089 & 507.4 & 1.170 & 24.623 \\
\hline $20 \%$ COG & $\mathrm{AA} / \mathrm{AqAV}$ & 0.1086 & 506.8 & 1.180 & 24.946 \\
\hline $15 \%$ COG & $\mathrm{AA} / \mathrm{AqAV}$ & 0.1085 & 513.3 & 1.150 & 23.078 \\
\hline $10 \%$ COG & $\mathrm{AA} / \mathrm{AqAV}$ & 0.1084 & 515.3 & 1.125 & 20.577 \\
\hline
\end{tabular}

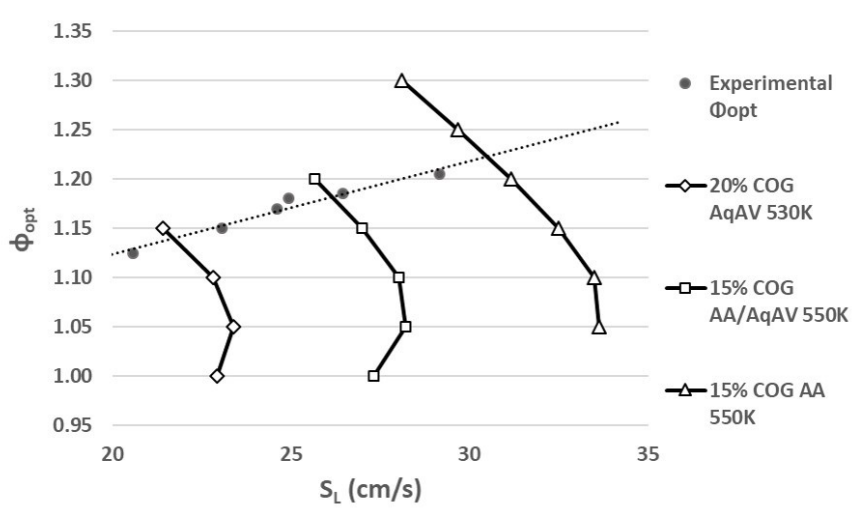

FIGURE 9. EXPERIMENTALLY DERIVED $\Phi_{\text {opt }}$ AGAINST MODELED $S_{L}$ FOR SELECTED FUEL BLENDS

Laminar flame speed for AqAV with 20\% COG over the range of $\Phi$ and at the same experimental conditions, are also 
plotted in Fig. 9. This line intersects the trend line for $\Phi_{\text {opt }}$ at an approximate $\Phi_{\text {opt }}$ of 1.13 . As emissions for $\mathrm{NH}_{3}$ and $\mathrm{NO}$ were not minimized at $\Phi=1.13$ (see Fig. 8) combustion instabilities may be responsible. Combustion instabilities were considerable at $\Phi$ $=1.15$, so operation at $\Phi=1.13$ was impractical. Thus, the AqAV with $20 \%$ COG blend was too unstable for further investigation.

The other two lines in Fig. 9 represent the modeled $\mathrm{S}_{\mathrm{L}}$ values for the two leading $\mathrm{AA}$ and $\mathrm{AA} / \mathrm{AqAV}$ blends at $550 \mathrm{~K}$ inlet, for the $\Phi$ range tested. Assuming the trend is robust across inlet temperature changes, at $550 \mathrm{~K}$ the $\Phi_{\text {opt }}$ for each blend will increase. The AA and AA/AqAV with $15 \%$ COG blends would have $\Phi_{\text {opt }}$ values $\sim 1.22$ (previously $\sim 1.185$ ) and $\sim 1.18$ (previously $\sim 1.15$ ) respectively.

\subsection{Reactor network modeling at increased pressure}

The improved reactor network model was used to predict the effect of increased pressure on $\Phi_{\text {opt }}$ in the primary stage. Inlet flows were scaled for 1.2 MPa for the two leading blends, to match the pressure ratio of the cycle analysis used in Section 4. Figure 10 shows the experimental results at atmospheric pressure and also modeled results (Okafor et al. mechanism) for atmospheric and 1.2 $\mathrm{MPa}$ pressure, for the leading AA blend, using the experimental inlet temperature. Emissions concentrations are given as wet. Modeling shows that at increased pressure, stable combustion is anticipated and both NO and $\mathrm{NH}_{3}$ concentrations are predicted to decrease considerably and be less sensitive to changes in $\Phi$. Similar findings were indicated for the leading AA/AqAV blend.

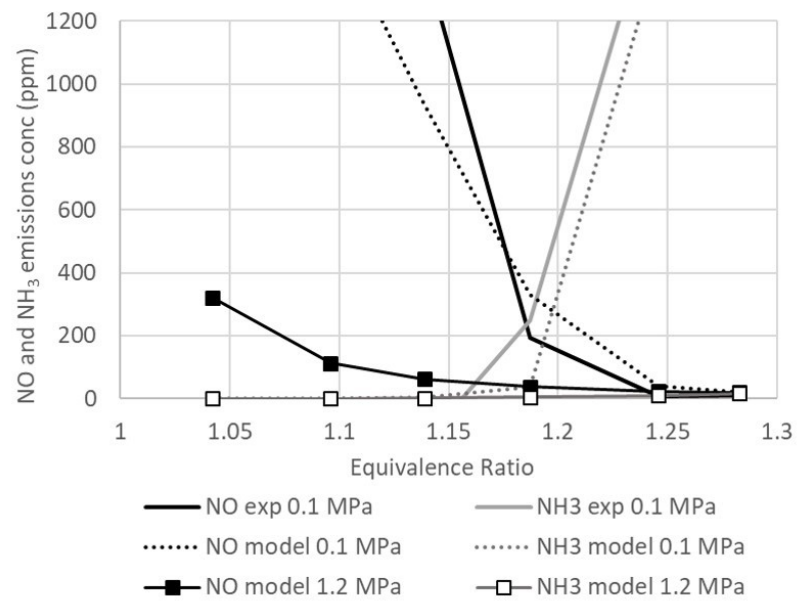

FIGURE 10. NO AND $\mathrm{NH}_{3}$ EMISSIONS BY EQUIVALENCE RATIO FOR AA WITH $15 \%{ }_{\text {vol }}$ COG WITH VARYING PRESSURE

\section{CYCLE INVESTIGATION USING ASPEN PLUS}

To gauge an approximate power output from the two leading experimental mixes, a simulated steady state thermodynamic cycle has been developed using Aspen Plus. Much of the cycle arrangement and many of the settings are the same as those used in the published preparatory study. Important settings not displayed in Fig. 11, are summarized in Table 3. The reader is referred to the previous study for further details and explanations [28]. All simulations fully converged.

TABLE 3. ASPEN PLUS THERMODYNAMIC CYCLE SETTINGS
\begin{tabular}{|lc|}
\hline Brayton Cycle & \\
GT efficiency & isen. $90 \%:$ mech. $99 \%$ \\
GT exit T (all cases) & $873 \mathrm{~K}$ \\
Compressor efficiency & \\
Recuperator min. T approach & isen. $88 \%:$ mech. $99 \%$ \\
Rankine Cycle & $30 \mathrm{~K}$ \\
Final condensation T & $393 \mathrm{~K}$ \\
HRSG exhaust T (all cases) & \\
Steam Turbine Efficiency & isen. $90 \%:$ mech. $99 \%$ \\
Pump efficiency & $80 \%$ overall \\
Pump pressure & $10 \mathrm{MPa}^{2}$ \\
Property Methods etc. & Peng-Robinson \\
Brayton cycle & IAPWS-95 \\
Rankine cycle & $78 \% \mathrm{~N}_{2}: 21 \% \mathrm{O}_{2}: 1 \%$ argon \\
Air composition & \\
\hline
\end{tabular}

The cycle consists of a Brayton cycle, followed by a Rankine bottoming cycle. Heat transfer from the compressed air alone is insufficient to both vaporize the ammonia and achieve the required preheat to aid reactivity in the fuel/air mix. Although waste heat on site could be used to preheat the inlet, the Brayton cycle incorporates the use of a recuperator, preheating the air/fuel mix to $550 \mathrm{~K}$, for a self-sustaining cycle. Although the likelihood of incorporating a Rankine cycle would naturally depend on the scale of operation, it is included to enable easy comparison with efficiencies of contemporary combined cycles.

This analysis focuses on the potential benefits of combining green ammonia with industrial waste stream ammonia, supported by $15 \%_{\mathrm{vol}} \mathrm{COG}$ (due to the experimental results), in three practical scenarios. As steelworks industrial waste stream ammonia is only practically available as either recovered anhydrous or $\sim 60 \%$ aqueous, achieving an ammonia feed with a $30 \%$ steam content requires combining an anhydrous source, e.g. green ammonia, with the aqueous stream in a fixed ratio (i.e. 50:50). The inlet mass flows for the three scenarios are scaled to the availability of 10 tonnes of by-product ammonia/day.

\subsection{Outline of Aspen Plus cycle scenarios}

The scenarios assume 15\% COG blending and are summarized in Table 4:

1. Green ammonia is imported and augmented with $\mathrm{AqAV}$ in a 50:50 blend (simplified to $70 \% \mathrm{NH}_{3}, 30 \% \mathrm{H}_{2} \mathrm{O}$ - as tested experimentally).

2. Industrial $\mathrm{NH}_{3}$ recovered from $\mathrm{AqAV}$ as 10 tonnes/day of AA, (e.g. using the PHOSAM process).

3. The same amount of green ammonia as for scenario 1, without the addition of AqAV to highlight the difference when not augmenting the green ammonia with AqAV. 


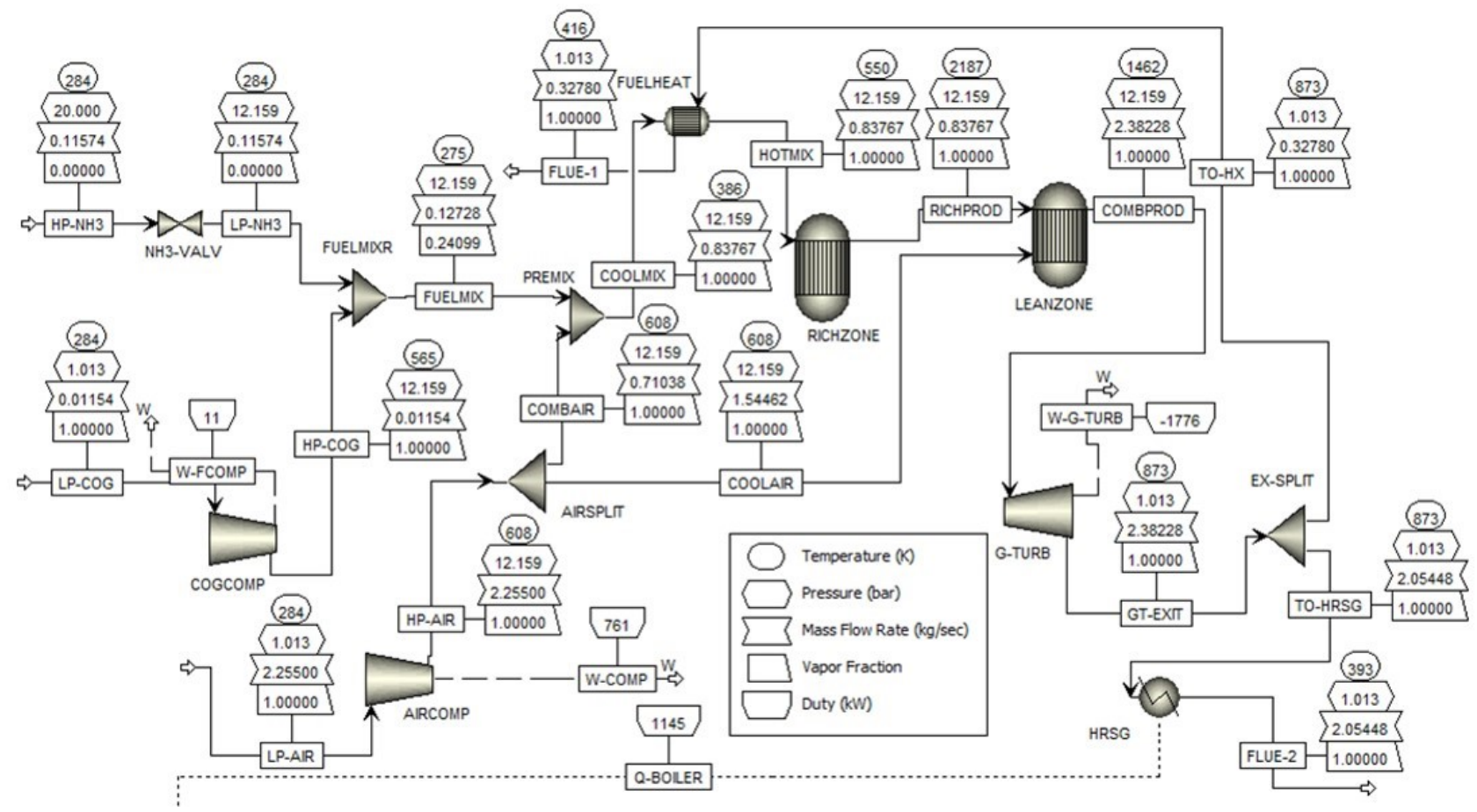

FIGURE 11. SCENARIO 2: 85\% ANHYDROUS AMMONIA/15\% COG, BRAYTON CYCLE WITH RECUPERATOR AND HRSG

TABLE 4. SCENARIOS FOR AMMONIA-BASED FUEL CYCLE

\begin{tabular}{|c|cccc|}
\hline Scenario & $\begin{array}{c}\text { Representative } \\
\text { Ammonia Fuel }\end{array}$ & $\begin{array}{c}\text { Green } \\
\text { Ammonia } \\
\text { (tonnes/day) }\end{array}$ & $\begin{array}{c}\mathrm{NH}_{3} \text { in AqAV } \\
\text { (tonnes/day) }\end{array}$ & $\Phi_{\text {opt }}$ \\
\hline 1 & $50: 50$ AA/AqAV & 25 & 10 & 1.15 \\
2 & AA & 0 & 10 & 1.2 \\
3 & AA & 25 & 0 & 1.2 \\
\hline
\end{tabular}

In the simplified 50:50 AA/AqAV blend, AqAV contains $40 \% \mathrm{NH}_{3}$. This $40 \%$ has a mass flow of 10 tonnes/day. Therefore, the ammonia component of AqAV represents $28.6 \%$ of the mass of all the ammonia in a 50:50 AA/AqAV blend. Thus, the total mass flow of $\mathrm{NH}_{3}$ into this cycle would be 35 tonnes/day. Approximate values of $\Phi_{\text {opt }}$ for the blends in the primary stage of combustion are given in Table 4 . Precise values are not important for the thermodynamic cycle as the fuel is assumed to be completely consumed in the second stage. Figure 11 shows the modeled Brayton cycle with recuperator, as applied to scenario 2 with no combustor losses. Naturally, as flow rates of the ammonia-based fuels increase, the demand for COG, as a fixed $15 \%$ vol of the overall composition, also increases. This is partly responsible for the increases in net power with higher flow rates of ammonia.

\subsection{Cycle summary}

A pressure reducing valve for the ammonia-based fuel, plus compressors for the COG and air feeds, supply a pressure of $\sim 1.2$ $\mathrm{MPa}$ to the combustion chamber. This pressure ratio is typical for GTs in the $~ 5 \mathrm{MW}$ scale [37]. The air compressor supplies combustion air to both the primary fuel-rich stage 'RICHZONE' and the secondary lean stage 'LEANZONE'.

The air splitter 'AIRSPLIT' ensures the primary reactor 'RICHZONE' is fed the amount of air to achieve the $\Phi_{\text {opt }}$ for each of the blends (see Table 4). The primary combustion air, heated by the compressor, is combined with the fuel mix in the mixer 'PREMIX'. Before entering the combustor, the premixed air and fuel is preheated to $550 \mathrm{~K}$ via the return of the minimum required percentage of turbine exhaust to the recuperator. Turbine exhaust not used for recuperation proceeds to a heat recovery steam generator (HRSG), which provides heat to the Rankine cycle (dotted line). The 'LEANZONE' reactor is fed with the remaining air from 'AIRSPLIT', which completes the combustion of the unburned fuel from the primary stage and cools the combustion products upstream of the turbine.

Both reactors are equilibrium reactors. This type of reactor is based on minimizing Gibbs free energy and is typically used for combustion and similar complex reaction simulations in Aspen Plus. Unlike with conventional gaseous fuels, the formation of $\mathrm{NO}_{\mathrm{x}}$ for fuels that contain nitrogen, such as ammonia, is far more dependent on kinetics than equilibrium. Aspen Plus is not compatible with the complex reaction mechanisms developed for modeling $\mathrm{NO}_{\mathrm{x}}$ formation in ammonia combustion, therefore Chemkin-Pro is used for modeling emissions (as in the preparatory study). Regardless, the effect on thermodynamic data, due to differences in modeling via equilibrium or kinetics for complete combustion of ammonia, is negligible. 
As the cycle is conceptual, heat and pressure losses from the combustor were modeled for no losses (adiabatic), 5\%,10\%, $15 \%$ and $20 \%$ of LHV to indicate the impact of combustor losses on the overall power and efficiency of the cycle.

\section{ASPEN PLUS CYCLE RESULTS AND DISCUSSION}

As Fig. 12 shows, the AA scenarios, i.e. 2 and 3, are more efficient overall than scenario 1 and, as the only difference is in scale of operation, they have the same efficiency.

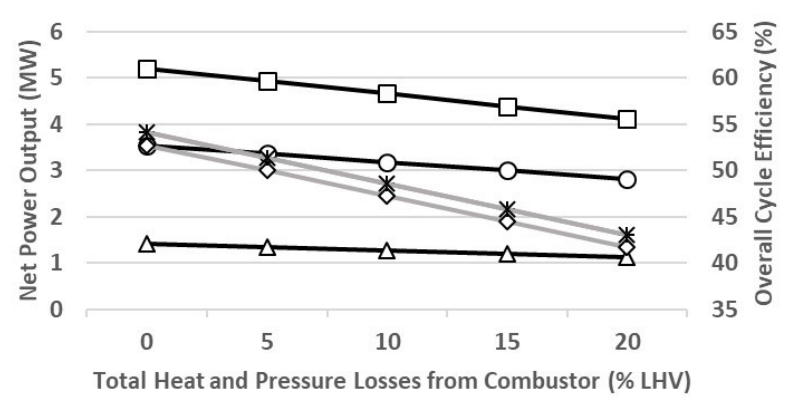

$\neg-$ Scenario 1 Power $\quad-\square$ Scenario 2 Power $\quad-\infty$-Scenario 3 Power

$\diamond$ Scenario 1 Effcy $\quad+$ Scenario 2 Effcy $\quad \times$-Scenario 3 Effcy

FIGURE 12. COMBINED CYCLE NET POWER AND EFFICIENCY AGAINST COMBUSTOR LOSSES FOR SCENARIOS 1 TO 3

Cycle efficiencies are based on fuel LHVs, as is the convention in combined cycle gas turbine efficiency values. At $10 \%$ combustor losses, the overall efficiencies of the AA with $\mathrm{COG}$ and the $\mathrm{AA} / \mathrm{AqAV}$ with $\mathrm{COG}$ cycles are $48.6 \%$ and $47.3 \%$ respectively.

The overall efficiency of scenario 1 is lower because a higher percentage of the exhaust flow, $26.7 \%$ at $10 \%$ combustor losses, is used in the recuperator to achieve the $550 \mathrm{~K}$ inlet temperature, leaving less exhaust heat for the Rankine cycle. Equivalent exhaust flow to the recuperator is $15.3 \%$ for scenarios 2 and 3.

Net electrical power available from scenarios 1, 2 and 3 (at $10 \%$ combustor losses) is 4.7, 1.3 and $3.2 \mathrm{MW}$ respectively, indicating an additional $\sim 1.5 \mathrm{MW}$ from the addition of industrial AqAV/COG to the green ammonia/COG. Utilizing the AqAV (and its allied COG) has improved the generating capacity of the green ammonia/COG by $\sim 4 \%$. This significant improvement in generating capacity supports the case for transporting green ammonia for co-firing with AqAV and COG.

Scenario 2, AqAV processed to AA, only generates 1.3 $\mathrm{MW}$, so less than the $\sim 1.5 \mathrm{MW}$ enhancement when using AqAV unprocessed. Processing AqAV into AA incurs additional energy, materials and infrastructure costs ahead of combustion. These costs are not factored here, but clearly would be detrimental to the cycle efficiency if included, further highlighting the benefit of using AqAV unprocessed.

Figure 13 shows that, when excluding the Rankine cycle, the cycle efficiency situation is reversed. The addition of AqAV to green ammonia increases the efficiency from $34.6 \%$ to $35.1 \%$ (at $10 \%$ combustor losses).
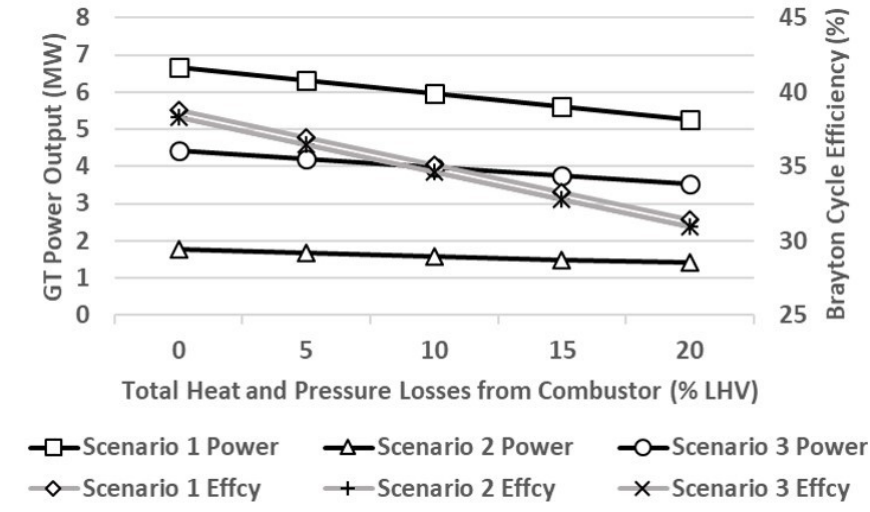

FIGURE 13. GT POWER AND BRAYTON CYCLE EFFICIENCY AGAINST COMBUSTOR LOSSES FOR SCENARIOS 1 TO 3

The sizing of the GT is $\sim 2 \mathrm{MW}$ greater in scenario 1 than 3. Larger GTs are inherently more efficient, so in reality, this differential would likely be greater. GTs of this scale do not justify the inclusion of bottoming cycles. Thus, for Brayton only cycles, efficiencies are maximized when adopting scenario 1, combining AA with AqAV.

\section{CONCLUSIONS AND FURTHER WORK}

This study has found experimentally that it is possible to combust $15 \%$ COG with both AA and a $70 \%$ AA, $30 \%$ water blend, to achieve a stable flame in a swirl burner using $>500 \mathrm{~K}$ preheat at atmospheric pressure. Also, under these conditions and at the approximate $\Phi_{o p t}, \mathrm{NO}$ and $\mathrm{NH}_{3}$ emissions can be minimized to combined levels of $<200 \mathrm{ppm}$ and $<300 \mathrm{ppm}$ for the $\mathrm{AA}$ and $\mathrm{AA} / \mathrm{AqAV}$ (with $15 \%_{\mathrm{vol}} \mathrm{COG}$ ) blends respectively. Further work is required to resolve the $\Phi_{\text {opt }}$ for the blends, to predict the ideal fuel-rich primary zone operating conditions. Trends indicate that $\Phi_{\text {opt }}$ correlates positively and linearly with $\mathrm{S}_{\mathrm{L}}$ for these mixes.

Cycle analysis shows that under typical system losses, combined cycle efficiencies of almost $50 \%$ are achievable for these blends, potentially higher if reactants are preheated via the utilization of waste heat on a steelworks site.

Without a bottoming cycle, AA/AqAV with COG achieves marginally higher efficiencies than AA with COG with efficiencies for both of $\sim 35 \%$. Given the scale of operation, i.e. $\sim 6 \mathrm{MW}$, this is the likely configuration for a modest-sized steel plant.

Transporting green ammonia to a steelworks site enables the use of COG as a support fuel. When augmented with ammonia from industrial wastewater, net power is increased by $\sim 47 \%$. This increase promotes and potentially enables the earlier uptake of green ammonia to power projects.

The next stage of investigation will be to experimentally verify $\Phi_{o p t}$ with change in inlet temperature, for the two leading blends, followed by the optimization of staged combustion to replicate the combustor in the cycle modeled in Aspen. Furthermore, the effects of increasing burner pressure on operability, emissions and $\Phi_{\text {opt }}$ will be evaluated. 


\section{ACKNOWLEDGMENTS}

The first author is funded through an EPSRC PhD Studentship. The project is also supported by FLEXIS (Flexible Integrated Energy Systems) a research project designed to develop energy-systems research capacity in South Wales.

The authors would also like to thank Mr. Steve Morris, facility manager at the Cardiff University Gas Turbine Research Centre, for his significant technical input and dedication to this work and technician Jack Thomas, for his help in setting up the experimental study.

\section{REFERENCES}

[1] Valera-Medina, A., Xiao, H., Owen-Jones, M., David, W. I. F., and Bowen, P. J. "Ammonia for power." Progress in Energy and Combustion Science Vol 69 (2018): pp. 63-102. DOI:10.1016/j.pecs.2018.07.001.

[2] Ahlgren, W. L. "The dual-fuel strategy: an energy transition plan." Proceedings of the IEEE Vol. 100 No. 11 (2012): $\quad$ 3001-3052. DOI:10.1109/JPROC.2012.2192469.

[3] Wilkinson, I. "The Role of "Green" Ammonia in Decarbonising Energy Systems: Practical Demonstration and Economic Considerations." NH3 Fuel Conference, Minneapolis (2017).

[4] Giddey, S., Badwal, S. P. S., Munnings, C. and Dolan, M. "Ammonia as a Renewable Energy Transportation Media." ACS Sustainable Chemistry \& Engineering Vol. 5 No. 11 (2017): pp. 10231-10239. DOI:10.1021/acssuschemeng.7b02219.

[5] Djinović, P. and Schüth, F. "Energy carriers made from hydrogen." P. and G. Moseley (Ed.) Electrochemical Energy Storage for Renewable Sources and Grid Balancing (2014): pp. 183-199. DOI:10.1016/B978-0444-62616-5.00012-7.

[6] Zamfirescu, C. and Dincer, I. "Using ammonia as a sustainable fuel." Journal of Power Sources Vol. 185 No. 1 (2008): pp. 459-465. DOI:10.1016/j.jpowsour.2008.02.097.

[7] U.S. Geological Survey. Mineral Commodity Summaries 2019.

[8] Remus, R., Roudier, S., Aguado-Monsonet, M. A. and Delgado Sancho, L. "Best available techniques - iron and steel production." Industrial Emissions Directive 2010/75/EU (2013): DOI:10.2791/97469.

[9] Kohl, A. L. and Nielsen, R. Gas Purification. Gulf Publishing, Houston (1997).

[10] Worldsteel Association. "World Steel in Figures 2018." from https://www.worldsteel.org/media-centre/pressreleases/2018/world-steel-in-figures-2018.html, accessed 4-2-2019.

[11] Razzaq, R., Li, C. and Zhang, S. "Coke oven gas: Availability, properties, purification, and utilization in China." Fuel Vol. 113 (2013): pp. 287-299. DOI:https://doi.org/10.1016/j.fuel.2013.05.070.
[12] Bermúdez, J. M., Arenillas, A., Luque, R. and Menéndez, J. A. "An overview of novel technologies to valorise coke oven gas surplus." Fuel Processing Technology Vol. 110 (2013): pp. 150-159. DOI:10.1016/J.FUPROC.2012.12.007.

[13] Teng, H. "Combustion modifications of batch annealing furnaces and ammonia combustion ovens for $\mathrm{NO}_{\mathrm{x}}$ abatement in steel plants." Journal of the Air and Waste Management Association Vol. 46 No. 12 (1996): pp. 1171-1178. DOI:10.1080/10473289.1996.10467552.

[14] Svoboda, K. and Diemer, P. "Catalytic decomposition of ammonia from coke-oven gas." Iron and Steel Engineer Vol. 67 No. 12 (1990): pp. 42-46.

[15] Industrial Efficiency Technology Database. "Coke making" from http://ietd.iipnetwork.org/content/cokemaking, accessed 1-8-2018.

[16] Worldsteel Association. "Steel and raw materials fact sheet." (2018): from https://www.worldsteel.org/steelby-topic/raw-materials.html, accessed 1-8-2018.

[17] Ekgauz, V. I., Pokryshkin, K. V., Tretiakova, G. D., Dementieva, N. V., Stepina, L. A., Putilov, A. V., Motovilova, N. K., Ryazanov, O. V., Kalinin, A. V., Blokhin, M. I., Grakhovskiy, A. V. and Sorokina, I. V. "Removal of ammonia from coke-oven gas at PAO Severstal' by a circulatory phosphate method." Coke and Chemistry Vol. 59 No. 3 (2016): pp. 92-100. DOI:10.3103/S1068364X16030030.

[18] Verkamp, F. J., Hardin, M. C. and Williams, J. R. "Ammonia combustion properties and performance in gas-turbine burners." Symposium (International) on Combustion Vol. 11 (1967): pp. 985-992. DOI:https://doi.org/10.1016/S0082-0784(67)80225-X.

[19] Kobayashi, H., Hayakawa, A., Somarathne, K. D. K. A. and Okafor, E. C. "Science and technology of ammonia combustion." Proceedings of the Combustion Institute Vol. 37 No. 1 (2019): pp. 109-133. DOI:10.1016/j.proci.2018.09.029.

[20] Valera-Medina, A., Morris, S., Runyon, J., Pugh, D. G., Marsh, R., Beasley, P. and Hughes, T. "Ammonia, methane and hydrogen for gas turbines." Energy Procedia Vol. 75 (2015): pp. 118-123. DOI:https://doi.org/10.1016/j.egypro.2015.07.205.

[21] Valera-Medina, A., Gutesa, M., Xiao, H., Pugh, D., Giles, A., Goktepe, B., Marsh, R. and Bowen, P. "Premixed ammonia/hydrogen swirl combustion under rich fuel conditions for gas turbines operation." International Journal of Hydrogen Energy Vol. 44 No. 16 (2019): DOI:10.1016/j.ijhydene.2019.02.041.

[22] Pugh, D., Bowen, P., Valera-Medina, A., Giles, A., Runyon, J. and Marsh, R. "Influence of steam addition and elevated ambient conditions on $\mathrm{NO}_{\mathrm{x}}$ reduction in a staged premixed swirling $\mathrm{NH}_{3} / \mathrm{H}_{2}$ flame." Proceedings of the Combustion Institute (2018): DOI:10.1016/j.proci.2018.07.091. 
[23] Valera-Medina, A., Marsh, R., Runyon, J., Pugh, D., Beasley, P., Hughes, T. and Bowen, P. "Ammoniamethane combustion in tangential swirl burners for gas turbine power generation." Applied Energy Vol. 185 (2016):

pp.

$1362-1371$.

DOI:10.1016/j.apenergy.2016.02.073.

[24] Valera-Medina, A., Pugh, D. G., Marsh, P., Bulat, G. and Bowen, P. "Preliminary study on lean premixed combustion of ammonia-hydrogen for swirling gas turbine combustors." International Journal of Hydrogen Energy Vol. $42 \quad$ No. $38 \quad$ (2017): DOI:10.1016/j.ijhydene.2017.08.028.

[25] Kurata, O., Iki, N., Matsunuma, T., Inoue, T., Tsujimura, T., Furutani, H., Kobayashi, H. and Hayakawa, A. "Performances and emission characteristics of $\mathrm{NH}_{3}$-air and $\mathrm{NH}_{3}-\mathrm{CH}_{4}$-air combustion gas-turbine power generations." Proceedings of the Combustion Institute Vol. 36 No. 3 (2017): pp. 3351-3359. DOI:10.1016/J.PROCI.2016.07.088.

[26] Okafor, E. C., Naito, Y., Colson, S., Ichikawa, A., Kudo, T., Hayakawa, A. and Kobayashi, H. "Experimental and numerical study of the laminar burning velocity of $\mathrm{CH}_{4}$ $\mathrm{NH}_{3}$-air premixed flames." Combustion and Flame Vol. 187 (2018): pp. 185-198. DOI:10.1016/j.combustflame.2017.09.002.

[27] Wendt, J. O. L. and Sternling, C. V. "Effect of ammonia in gaseous fuels on nitrogen oxide emissions." Journal of the Air Pollution Control Association Vol. 24 (1974): pp. $1055-1058$. DOI:10.1080/00022470.1974.10470013.

[28] Hewlett, S. G., Valera-Medina, A., Pugh, D. G. and Bowen, P. J. "Gas Turbine Co-Firing of Steelworks Ammonia with Coke Oven Gas: A Fundamental and Cycle Analysis." Proceedings of the ASME Turbo Expo (2019): pp. GT2019-91404. DOI:10.1115/GT201991404.

[29] Tian, Z., Li, Y., Zhang, L., Glarborg, P. and Qi, F. "An experimental and kinetic modeling study of premixed $\mathrm{NH}_{3} / \mathrm{CH}_{4} / \mathrm{O}_{2} / \mathrm{Ar}$ flames at low pressure." Combustion and Flame Vol. 156 No. 7 (2009): pp. 1413-1426. DOI:10.1016/j.combustflame.2009.03.005.

[30] Pugh, D. Combustion characterisation of compositionally dynamic steelworks gases Cardiff University PhD Thesis (2013): Retrieved from http://orca.cf.ac.uk/58006/.

[31] Li, S., Zhang, S., Zhou, H. and Ren, Z. "Analysis of airstaged combustion of $\mathrm{NH}_{3} / \mathrm{CH}_{4}$ mixture with low $\mathrm{NO}_{x}$ emission at gas turbine conditions in model combustors." Fuel Vol. $237 \quad$ (2019): DOI:10.1016/j.fuel.2018.09.131.

[32] Somarathne, K. D. K. A., Hatakeyama, S., Hayakawa, A. and Kobayashi, H. "Numerical study of a low emission gas turbine like combustor for turbulent ammonia/air premixed swirl flames with a secondary air injection at high pressure." International Journal of Hydrogen Energy Vol. 42 No. 44 (2017): pp. 27388-27399.
DOI:10.1016/j.ijhydene.2017.09.089.

[33] Smith, G. P., Golden, D. M., Frenklach, M., Moriarty, N. W., Eiteneer, B., Goldenberg, M., Bowman, C. T., Hanson, R. K., Song, S., Gardiner, Jr., W. C., Lissianski, V. V., Qin, Z. "GRI-Mech 3.0", from http://www.me.berkeley.edu/gri_mech/, accessed 5-22020.

[34] International Organization for Standardization. "ISO 11042-1:1996 - Gas turbines - Exhaust gas emission Part 1: Measurement and evaluation." from https://www.iso.org/standard/19022.html, accessed 1811-2019.

[35] European Union. "Directive (EU) 2015/ 2193 of the European Parliament and of the Council on the limitation of emissions of certain pollutants into the air from medium combustion plants." Official Journal of the European Union EN Vol. 451 No. 354 (2014): pp. 134 23.

[36] Li, J., Huang, H., Kobayashi, N., He, Z. and Nagai, Y. "Study on using hydrogen and ammonia as fuels: Combustion characteristics and $\mathrm{NO}_{\mathrm{x}}$ formation." International Journal of Energy Research Vol. 38 No. 9 (2014): pp. 1214-1223. DOI:10.1002/er.3141.

[37] Siemens. "Siemens products and services - energy power generation - gas turbines" from https://new.siemens.com/global/en/products/energy/po wer-generation/gas-turbines.html, accessed 6-8-2019. 